\title{
Assessment of prevalence of Anxiety in adult population and development of anxiety scale: A study of 819 patients with anxiety disorder
}

\author{
Zaqia Bano' ${ }^{1}$ Maria Ejaz², Ishtiaq Ahmad ${ }^{3}$
}

\begin{abstract}
Objective: To develop an indigenous anxiety scale for adults and to assess the prevalence of anxiety among the adults.

Methods: Descriptive explanatory research design was carried out from $1^{\text {st }}$ January 2018 to $31^{\text {st }}$ May 2019 at the Department of Psychology, University of Gujrat. The indigenous anxiety scale for adults was used for data collection. Scale consisted on three sub scales which are used to assess the cognitive symptoms, behavior and physiological symptoms through CFA value and alpha reliability. Sample of adequacy is .965, Confirmatory Factor Analysis value .914, alpha reliability .974 were taken as standard. In cognitive symptoms subscale's alpha was 0.958 , Behavior subscale .943 and Physiological symptoms subscale alpha was a .912.

Results: The prevalence of anxiety in 20-29 years individuals exhibited 17.5\% (male 38.8\%; female 62.2) symptoms of anxiety. 30-39 Years people showed $12.9 \%$ (male $=56.9 \%$; female $=43.1 \%$ ), $40-49$ years individuals showed $16.5 \%$ of anxiety and in late adulthood 50-60 years old people showed highest level of anxiety $22.10 \%$ (male $=68.3 \%$; female $=31.7$ ).

Conclusion: The anxiety scale for adults is a reliable indigenous scale for measuring anxiety in adults. Further, the prevalence rate of anxiety in adult population is alarming indication and middle and late adulthood suffered more anxiety as compare to early adulthood.
\end{abstract}

KEYWORDS: Anxiety scale, Behavior, Cognitive, Confirmatory factor analysis, Physical response subscales and prevalence, Reliability.

doi: https://doi.org/10.12669/pjms.37.2.2158

How to cite this:

Bano Z, Ejaz M, Ahmad I. Assessment of prevalence of Anxiety in adult population and development of anxiety scale: A study of 819 patients with anxiety disorder. Pak J Med Sci. 2021;37(2):472-476. doi: https://doi.org/10.12669/pjms.37.2.2158

This is an Open Access article distributed under the terms of the Creative Commons Attribution License (http://creativecommons.org/licenses/by/3.0), which permits unrestricted use, distribution, and reproduction in any medium, provided the original work is properly cited.

1. Dr. Zaqia Bano, PhD.

Department of Psychology,

2. Maria Ejaz,

Department of Psychology

3. Dr. Ishtiaq Ahmad, FCPS. FRCS

Department of Surgery,

Al-Nafees Medical College, Isra University, Islamabad, Pakistan.

1-3: University of Gujrat,

Gujrat, Pakistan.

Correspondence:

Dr. Zaqia Bano,

Assistant Professor, Department of Psychology

University of Gujrat, Gujrat, Pakistan.

Email: zaqia.bano@uog.edu.pk

* Received for Publication:

December 28, 2019

* $1^{\text {st }}$ Revision Received:

* $\quad 2^{\text {nd }}$ Revision Received:

* Accepted for Publication:
June 27, 2020

August 11, 2020

November 3, 2020

\section{INTRODUCTION}

Anxiety is a normal human emotion and it may be a result of stress. The pathological anxiety is defined as an excessive, unpredicted, unmanageable, and overwhelming emotional response to apparent and looming threat. Anxiety may be manifested by constant worry, tension and biological symptoms like palpitation, increase blood pressure and uneasiness. ${ }^{1,2}$ Anxiety disorder is the most prevalent mental health issue and significantly effects the personal, social and occupational life of the individuals. Furthermore, anxiety intensely influenced the quality of life of individuals and enhances the chances of heart problem, risk of suicide and other medical issues. ${ }^{3}$ 
A study conducted by Dhal et al for assessing anxiety in adults concluded that the males who suffered anxiety had poor marital relation, drug addiction, low intake of fruit and vegetables, low income and are at high risk of developing cardio vascular problems and Asthma. ${ }^{4}$

A large scale population survey by Bandelow and Michaelis reported that up to $33.7 \%$ of the population are affected by anxiety disorder during their life. ${ }^{5}$ The results indicated that the anxiety disorders are the most prevalent, disturbing, persistent, chronic, utmost disabling disorders and frequently comorbid with depression and substance abuse disorder. ${ }^{6}$ A recent British survey results indicated that almost $16 \%$ of the population suffering from pathological anxiety. ${ }^{7}$ According to a WHO report about 40 million Americans around the age of 18 and above are suffering from anxiety. It further explained that almost $27 \%$ old age people showed anxiety symptoms and among them $14 \%$ is experiencing severe anxiety disorder. ${ }^{8}$

A study by Ritchie and Roser observed that worldwide women suffered anxiety twice then males. In the overall population of the world, 170 million females (62\% females) suffered anxiety disorder. ${ }^{9}$ Maya and colleagues ${ }^{10}$ also reported that women experienced more anxiety $(63 \%)$ then males $(40 \%)$. Among young and old age anxiety patients, the older adult patients show more symptoms of anxiety. ${ }^{11}$ Especially, adolescents at high risk and even in crises situation they are more prone to anxiety disorder, irritability and restlessness. ${ }^{12,13}$

To measure the anxiety level, so far there is no indigenous scale is developed or available in Pakistan. We are relying on the scales developed by the Western world that are having a totally different demographic, socio-economic, religious, environmental and cultural pattern from Pakistan. Moreover, these scales are not in our native language and neither covers the all aspects of our life patterns mentioned before. There is a dire need to develop a standardized scale covering all aspects in native language. This self-administered scale can be used in both clinical and nonclinical settings, local surveys and by social workers. Further, ASA will measure the cognitive, behavior and physiological aspects of anxiety and levels of anxiety as well. This study was conducted with an objective to develop an indigenous anxiety scale for adults and to assess the prevalence of anxiety among the adults.

\section{METHODS}

This descriptive explanatory research design study was conducted at the Department of Psychology, University of Gujrat from $1^{\text {st }}$ January 2018 to $31^{\text {st }}$ May 2019. Ethics Committee meeting held on 23.10.2018 and approved by Advanced Studies \& Research Board in meeting held on 12.02.2019, under Vide notification No. UOG/ ASRB/Psychology/03/17677 dated March 1, 2019. A total of 819 participants from genders between the ages of 19 to 60 years were selected through convenient sampling technique from different areas of District Gujrat. Both genders, clinical and non-clinical population with anxiety disorder were included in the study. The individuals below the age of 18 years, having physical or intellectual disability and diagnosed patient with other psychiatric disorders were also excluded from study. Two scale Demographic information Form which 'consisted of personal information, age, gender, education and birth order and newly developed anxiety scale for adults ${ }^{14}$ were used to measure anxiety in adults. After the proper permission of Institution authorities and Departmental research review committee the participants were approached in community and Hospital by the researcher. Before data collection confidentiality were ensured to the participants.

Data analysis: In order to interpret the data IBM SPSS V-21, and AMOS Graphics was used. Descriptive statistics was used to measure the prevalence of the anxiety. Reliability analysis, correlation analysis and Dimension reduction was used for exploratory factor analysis. AMOS Graphics was used for the purpose of Confirmatory factor analysis.

\section{RESULTS}

A total 819 participant's between the age range of 30 years were assessed with a mean age of 2060 years from both sex $($ male $=473$, female $=346$ ). Majority of the patients $(n=143,17.5 \%)$ were from $3^{\text {rd }}$ decade of life followed by $5^{\text {th }}$ decade i.e. $16.5 \%$ $(n=135)$ as shown in Table-I.

In scale development, for measuring exploratory factor analysis factors were fixed on 5.00. After extraction of the items and Varimax Rotation final 45 Item remained on Anxiety Scale for Adults (ASA) $(n=334)$. Cognitive symptoms of anxiety consisted 18 loaded items. Item 1(0.606), 2(0.683), $3(0.672), \quad 4(0.587), 5(0.618), \quad 6(0.666), \quad 7(0.617)$, $8(0.523), 9(0.678), 10(0.608), 11(0.571), 12(0.658)$, 
Table-I: Frequency of age and sex distribution across various age groups $(\mathrm{N}=819)$.

\begin{tabular}{llccc}
\hline Age group & Gender & $F$ & $\%$ & Total $\%$ \\
\hline (20-29) Years & Male & 76 & 38.8 & $143(17.5 \%)$ \\
& Female & 120 & 62.2 & \\
(30-39) Years & Male & 107 & 56.9 & $106(12.9 \%)$ \\
& Female & 81 & 43.1 & \\
(40-49) Years & Male & 139 & 65 & $135(16.5 \%)$ \\
& Female & 75 & 35 & \\
(50-60) Years & Male & 151 & 68.3 & $181(22.10 \%)$ \\
& Female & 70 & 31.7 & \\
\hline
\end{tabular}

Note: $\mathrm{f}=$ stands for Frequency, $\%=$ Percentage of Gender.

13(0.590), 14(0.562), 15(0.560), 16(0.560), 17(0.640) and 18(554). Whereas, on behavior symptom of anxiety sub-scale comprised 16 items as items no $19(0.489), 20(0.576), 21(0.613), 22(0.611) .23(0.710)$, $24(0.614), 25(0.591), 26(0.600), 27(0.629), 28(0.615)$, 29(0.623), 30(0.632), 31(0.605), 32(0.550), 33(0.78), and item no 34(0.586). Furthermore, Physiological symptoms of anxiety sub-scale consisted on 11 items. Item no 35 value was $(0.625), 36(0.585)$, 37(0.629), 38(0.617), 39(0.684), 40(0.711), 41(0.689), $42(0.616), 43(0.615), 44(639)$, and 45(0.678). Sample adequacy of the ASA was highly adequate such as KMO was 0.967, Chi-Square 10155.416, df, 990 at 0.00 level of significance.

Overall Cronbach's Alpha reliability of the Anxiety Scale for Adults was $0.974(\mathrm{~N}=334)$. Further, reliability of the three subscales of ASA was highly significant such as Cognation Symptoms of anxiety was 0.958, Behavior Symptoms 0.943 and Physiological Symptoms subscale reliability was 0.912 .

Prevalence of severity of anxiety in both genders is shown in Table-II. Score ranges above 117 showed High level of anxiety, from 59-117, moderate and below 59 scores exhibited as low level of anxiety. Frequency of severity of moderate anxiety were highest ie $53.96 \%(n=442)$ whereas mild anxiety was found in only 5.98\% ( $=149)$ patients in both gender.

Frequency of severity of anxiety in both gender in different age groups is shown in Table-III. Severe
Table-III: Frequency of severity of anxiety among both Gender in different age groups $(\mathrm{N}=819)$.

\begin{tabular}{llc}
\hline Age & Score & $N(\%)$ \\
\hline (20-29) Years & Severe & $64(19.5 \%)$ \\
& Moderate & $118(26.7 \%)$ \\
& Mild & $14(28.6 \%)$ \\
$(30-39)$ Years & Severe & $81(24.7 \%)$ \\
& Moderate & $100(22.6 \%)$ \\
& Mild & $7(14.3 \%)$ \\
$(40-49)$ Years & Severe & $98(29.9 \%)$ \\
& Moderate & $102(23.1 \%)$ \\
$(50-60)$ Years & Mild & $14(28.6 \%)$ \\
& Severe & $85(25.9 \%)$ \\
& Moderate & $112(27.6 \%)$ \\
& Mild & $14(28.6 \%)$ \\
\hline
\end{tabular}

anxiety were observed highest in $5^{\text {th }}(n=98,29.9 \%)$ and $6^{\text {th }}$ decade $(n=85,25.9 \%)$, whereas moderate severity of anxiety were observed in $3^{\text {rd }}(n=118$, $26.7 \%)$ and $6^{\text {th }}$ decade $(n=112,27.6 \%)$ of life. The frequency of mild anxiety is almost same ie $2 \mathrm{~h} 8.6 \%$ in $3^{\text {rd }}, 5^{\text {th }}$ and $6^{\text {th }}$ decade of life.

\section{DISCUSSION}

The main objective of the current study was to develop a valid measure of anxiety for adults. Anxiety scale for adults (ASA) developed according to the beck model (Cognition, Behavior and Physiological symptoms). In exploratory factor analysis the factor were loaded on 0.5 level of significance and after loading remained 110 items. Exploratory factor analysis is important in the factor analysis process; exploratory factor analysis explored the variables and generates factors. This process provided the guideline about the number of factor. ${ }^{15}$ For testing the adequacy of the data KMO was 0.967 on 0.00 level of significance which was sufficiently adequate. ${ }^{16}$

Confirmatory factor analysis was conducted to confirm the factor given by EFA. CFA unlike EFA provide a complete system to check the testing model. ${ }^{17}$ A modification index was run to check the problematic items and increase the value of Comparative fit index (CFI). The RMESA values

Table-II: Frequency of severity of anxiety among both gender $(\mathrm{N}=819)$.

\begin{tabular}{llccc}
\hline \multicolumn{2}{l}{ Severity of anxiety } & Total $N=819$ & Male $n=473(57.76 \%)$ & Female $n=346(42.24 \%)$ \\
\cline { 2 - 5 } & & $(\%)$ & $F(\%)$ & $F(\%)$ \\
\hline Severe & (Above117) & $328(40 \%)$ & $193(58.8 \%)$ & $135(41.2 \%)$ \\
Moderate & (59-117) & $442(53.96 \%)$ & $244(55.2 \%)$ & $198(44.8 \%)$ \\
Mild & (Below 59) & $49(5.98 \%)$ & $36(73.5 \%)$ & $13(26.5 \%)$ \\
\hline
\end{tabular}


also tell the developer how well the model is fit. ${ }^{18}$ The value of Root mean Squared error of approximate is .51 which is less then 0.08 which showed the model is good fit. The value of RMESA should be $\leq 8$ for model fitness and if it is $\leq .05$ then it means the model is closed fit and in this case the model is closed fit. ${ }^{19}$

The value of Turker Lewis index (TLI) is .910 which means the model is approximately fit. The value of TLI $<.90$ means that the model is inadequate fit. But in this case the value of TLI is greater then .90 so we can say that the model is fit and there is no need of substantial changes in the data. The value of GFI is .812 which is closed to .09 and shows that the model is closed to adequate fit. The range of GFI is between 0 to one and it will increase as the sample increase. ${ }^{20}$ The value of CMIN/DF is 1.882 which is less than three and show the fitness of model. ${ }^{21} \mathrm{Chi}$ square test was used to check the goodness of the test the $p$ is .00 which is less then .05. It showed that the model is satisfactory fit. ${ }^{22}$ he value of Comparative fit index (CFI) is .914 which is greater than .90 show that the model is satisfactory fit. ${ }^{23}$ So the result shows that the model is adequately satisfacstory. The reliability of the scale was (0.974) and the reliability of the three subscales cognitive (0.958), behavior (0.943) and physiological symptoms (0.912) were highly significant Research. Further, the value of Cronbach's alpha should be between 0 to will be considered significant. ${ }^{24}$

Further, result showed the prevalence of anxiety was higher in males in middle and late adulthood as age ranges $30-39$ years (56.9\%); $40-49$ years male showed higher anxiety symptoms ((65\%), 50-60 years $68.3 \%$ as compare to females $43.1 \%$, $35 \%$ and 31.7 at the age of $30-39,40-49$ and $50-60$ years of age. Whereas, in early adulthood from 20-29 years of age female exhibited higher anxiety $62.2 \%$ as compare to male as $38.8 \%$. The prevalence of anxiety around the world varies 2.5 to 6.5 from country to country. Global estimation of anxiety disorder 2016 shows that 275 million people experienced anxiety. Among those peoples $62 \%$ were females and $38 \%$ were males ${ }^{25}$; the prevalence rate of anxiety over life time is $31 \% .^{26}$ Malathy Lyer explained ${ }^{27} 38$ million (7.5\%) Indian suffered anxiety disorder. Further, in Iran $12 \%$ males and $19.4 \%$ females experienced anxiety disorder. ${ }^{28}$ Ministry of Health Iraq explained that anxiety disorder in Iraq was $13.8 \% .^{29}$ Literature reported that the prevalence of anxiety has significantly increased during last ten years in Pakistan, as
$60 \%$ people exhibited the symptoms of anxiety. ${ }^{30}$ According to the 2017 report of Institute of Health Metrics and Evaluation (IHME), anxiety is a most disabling issue and affects around $34.0 \%$ of the population in Pakistan. ${ }^{31}$

In last decade anxiety has become hazardous problem in Pakistan. Although epidemiological studies of anxiety disorders are available. Current study estimation showed the prevalence of anxiety such as 328(40\%) individual showed high, 442(54\%) moderate level and 49(6\%) people respond low level of anxiety. Among the gender females suffered from more anxiety in early adulthood whereas male experienced pathological anxiety in middle and late adulthood. One current study conducted in Sialkot is also in line that $89(17.8 \%)$ University students showed severe anxiety and $46.8 \%$ exhibited extereme sever anxiety symptoms. ${ }^{32}$ Futhermore 14 years and above adolescents in Karachi suffered 11\% anxiety disorders symptoms. ${ }^{33}$ Researcher ${ }^{34}$ have explained that when anxious person's age increased the level of anxiety was also significantly increased.

Limitations of the study: Data was collected in the District Gujrat, so the findings have the issue of generalizability. Current study focused on adolescent population and data was gathered only from institutions. Precipitating factors of anxiety in adolescents could not become the part of the study. The construct of 'Anxiety' was measured as a whole, although self-reported anxiety scale was comprised the three factors of anxiety those factors (Cognitive, behavior and physiological symptoms of anxiety) were not individually evaluated.

\section{CONCLUSION}

The anxiety scale for adults is a reliable indigenous scale for measuring anxiety in adults. Further, the prevalence rate of anxiety in adult population is alarming indication and middle and late adulthood suffered more anxiety as compare to early adulthood.

\section{Grant Support \& Financial Disclosures: None.}

\section{REFERENCES}

1. American Psychiatric Association. Diagnostic and statistical manual of mental disorders (5th ed.). Washington, DC. 2013:312-322.

2. Alzahrani M, Alfahaid F, Almansour M, Alghamdi T, Ansari T, Sami, W, et al. Prevalence of generalized anxiety disorder and major depression in health-care givers of disabled patients in Majmaah and Shaqra cities, Kingdom of Saudi Arabia. Int J Health Sci. 2017;11(3):9-13. 
3. Ammar G, Naja WJ, Pelissolo A. Troubles anxieux resistants: revue des strategies de traitements medicamenteux. Lencephale. 2015;41(3):260-265.

4. DahlAA,DahlCF. Aretheregenderdifferencesinimpairment associated with high social anxiety? A communitybased study. J Anxiety Disord. 2010;24(5):487-493. doi: 10.1016/j.janxdis.2010.03.005

5. Bandelow B, Michaelis S. Epidemiology of anxiety disorders in the 21st century. Dialogues Clin Neurosci. 2015;17(3):327-335.

6. Kessler RC, Chiu WT, Demler O, Merikangas KR, Walters EE. Prevalence, severity, and comorbidity of 12-month DSM-IV disorders in the National Comorbidity Survey Replication. Arch Gen Psychiatry. 2005;62(6):617-627.

7. Facts \& Statistics | Anxiety and Depression Association of America, ADAA. 2019. Website: [https://adaa.org/ about-adaa/press-room/facts-statistics.] Accessed on Jan 20, 2020

8. National Alliance on Mental health, 2017. Website: [https://www.nami.org/learn-more/mental-healthconditions/anxiety-disorders]. Accessed on Jan 26, 2020

9. Ritchie H, Roser M. Mental health. 2018. Website: [https//ourworldindata.org/mental-health]. Accessed on Jan 15,2020

10. Maya A, Aderka IM. Gender differences in social anxiety disorder. J Clin Psychol. 2018;74(7):1730-1741. doi: 10.1002/ jclp.22624

11. Altunoz U, Kokurcan A, Kirici S, Bastug G, Ozel-Kizil E. Clinical characteristics of generalized anxiety disorder: older vs. young adults. Nord J Psychiatry. 2017;72(2):97102. doi: $10.1080 / 08039488.2017 .1390607$

12. Imran N, Zeshan $M$, Pervaiz Z. Mental health considerations for children \& adolescents in COVID-19 Pandemic. Pak J Med Sci. 2020;36(COVID19-S4):S67-S72. doi: 10.12669/pjms.36.COVID19-S4.2759

13. Imran $\mathrm{N}$, Aamer I, Sharif MI, Bodla $\mathrm{ZH}$, Naveed $\mathrm{S}$. Psychological burden of quarantine in children and adolescents: A rapid systematic review and proposed solutions. Pak J Med Sci. 2020;36(5):1106-1116. doi: 10.12669 / pjms.36.5.3088

14. Ejaz M. Development and Psychometric Evaluation of Anxiety Scale For Adults: Translation And Adaptation (Unpublished M.Phil. thesis) 2019. University of Gujrat, Pakistan.

15. Carpenter S M. Ten Steps in Scale Development and Reporting: A Guide for Researchers. Communication Commun Methods Measures. 2018;12(1):25-44. doi: 10.1080/19312458.2017.1396583

16. Cerny CA, Kaiser HF. A study of a measure of sampling adequacy for factor-analytic correlation matrices. Multivariate Behav Res. 1977;12(1):43-47.

17. Dillon WR, Goldstein M. Multivariate Analysis: Methods and Applications. John Wiley and Sons. New York. 1984;254-255.

18. Byrne BM. Structural equation modeling with EQS and EQS/ Windows: Basic concepts, application and programming. Lawrence Erlbaum Associates. 2006;125-147.

19. Browne $M$ W, Cudeck R. Alternative ways of assessing model fit. In Bollen K A, Long J S. [Eds.] Testing structural equation models. Newbury Park, CA. 1993;136-162.

20. Tucker L R, Lewis C. A reliability coefficient for maximum likelihood factor analysis. Psychometrika. 1973;38:1-10. doi: 10.1007/BF02291170

21. Cochran W. The Test of Goodness of Fit. Ann Appl Stat. 1952;23(3):315-345. doi: 10.1214/aoms/1177729380
22. Hoyle R H, Panter A T. Writing about structural equation models. In R. H. Hoyle (Ed.), Structural equation modeling: Concepts, issues, and applications. Thousand Oaks, CA. Sage Publications, Inc.US. 1995;158-176.

23. Byrne B M. Structural equation modeling with EQS and EQS/Windows: Basic concepts, application and programming. Lawrence Erlbaum Associates. 2006;Pp 125-147.

24. Tavakol M, Dennick R. Making sense of Cronbach's alpha. Int J Med Educ. 2011;2:53-55. doi: 10.5116/ijme.4dfb.8dfd

25. Ritchie H, Roser M. MentalHealth. 2019. Retrieved from https://ourworldindata.org/mental-health

26. Katzman MA, Bleau P, Blier P, Chokka P, Kjernisted $\mathrm{K}$, Van Ameringen $\mathrm{M}$ et al. Canadian clinical practice guidelines for the management of anxiety, posttraumatic stress and obsessive-compulsive disorders. BMC Psychiatry. 2014;14(Suppl1):S1. doi: 10.1186/1471-244X-14-S1-S1

27. Malathy Iyer. $7.5 \%$ Indians suffer from mental disorders: WHO Report", Times of India, 2017 February 25. Mental Health Survey Report (October, 2016). National Institute of Mental Health and Neurosciences, Bengalaru.

28. Hajebi A, Motevalian S A, Rahimi-Movaghar A, Sharifi $\mathrm{V}$, Amin-Esmaeili M, Radgoodarzi R et al. Major anxiety disorders in Iran: prevalence, sociodemographic correlates and service utilization. BMC Psychiatry. 2018;18(1):261. doi: 10.1186/s12888-018-1828-1832

29. Alhasnawi S, Sadik S, Rasheed M, Baban A, Al-Alak M M, Othman A Y. Iraq Mental Health Survey Study Group. The prevalence and correlates of DSM-IV disorders in the Iraq Mental Health Survey (IMHS). World Psychiatry. 2009;8(2):97-109.

30. Ahmed B, Enam F S, Iqbal Z, Murtaza G, Bashir S. Depression and Anxiety: A Snapshot of the Situation in Pakistan. Int J Neurosci Biobehav Sci. 2016;4(2):32-36. doi: 10.13189/ijnbs.2016.040202

31. Institute of Health Metrics and Evaluation. 2017. http:// www.healthdata.org/pakistanE

32. Asif S, Mudassar A, Shahzad TZ, Raouf M, Pervaiz T. Frequency of depression, anxiety and stress among university students. Pak J Med Sci. 2020;36(5):971-976. doi: $10.12669 /$ pjms.36.5.1873

33. Sarwat A, Ali SMI, Ejaz MS. Mental health morbidity in children: A hospital based study in child psychiatry clinic. Pak J Med Sci. 2009;25(6):982-985.

34. Bandelow B, Michaelis S. Epidemiology of anxiety disorders in the 21st centuryEpidemiology of anxiety disorders in the 21st centuryDepartment of Psychiatry and Psychotherapy, University Medical Centre, Göttingen, Germany;Epidemiology of anxiety disorders in the $21^{\text {st }}$ century. Dialogues Clin Neurosci. 2015;17(3):327-335.

\section{Author`s Contribution:}

ZB conceived, designed methodology, statistical analysis, manuscript writing, \& editing of manuscript. She is also responsible and accountable for the accuracy or integrity of the work.

ME did data collection, statistical analysis and responsible and accountable for the accuracy or integrity of the work.

IA did review, editing and final approval of manuscript. 